\title{
When social sciences meet the bio-physical sciences: energetics perspectives for socio-ecological sustainability.
}

\author{
Dario Padovan ${ }^{1, *}$ \\ ${ }^{1}$ Department of Culture, Politics and Society - University of Turin
}

\begin{abstract}
In this chapter, the author tries to suggest that social sciences can help the understanding of current critical socio-ecological dynamics. Social sciences have always been suspicious of idea that social phenomena can be investigated from a materialist point of view. Despite the idea that in every society there is a clearly determined group of phenomena separable from those that form the subject matter of other sciences of nature, this reflection suggests that social scientists developed significant analysis of the relationships between society and nature. Here the author tries to show that a social look could cast new lights upon the connections and interdependences between economic crisis and ecological crisis. The basic idea is that the decreasing natural fertility of capital is the cause of the decreasing global rate of profit of global economy and consequently the cause of the acceleration of new ways of nature appropriation, which can only deepen the current crisis.
\end{abstract}

\section{Sociology and nature}

For decades, sociologists investigated the society as if materiality did not matter [1]. The decoupling of society and nature, however, had not be written in the evolution of social sciences.

Karl Marx grounded all his analysis of capitalist society-starting from commodity and ending with fictitious capital-on the dialectic of society and nature.

"The labour process, as we have just presented it in its simple and abstract elements, is purposeful activity aimed at the production of use-values. It is an appropriation of what exists in nature for the requirements of man. It is the universal condition for the metabolic interaction (Stoffwechsel) between man and nature, the everlasting nature-imposed condition of human existence, and it is therefore independent of every form of that existence, or rather it is common to all forms of society in which human beings live" [2].

The characteristic of this metabolic interaction is that nature is humanised while men are naturalised. Its form is in each case historically determined. Labourpower, that 'material of nature transferred to a human organism', acts on the materials of nature which are outside man; it is therefore through nature that nature is transformed. Men incorporate their own essential forces into natural objects which have undergone human labour. Through the same process, natural things gain a new social quality as use-values, increasing in richness over the course of history.

Sociologists such as Max Weber, even though they reached the conclusion that society and nature must be separated for theoretical and empirical reasons, were often fascinated by the choice to admit the "non- human" to their ontology. In a very caustic overview that strongly criticized Wilhelm Ostwald's book on social energetics [3] Max Weber observed:

"Although the foregoing observations might have given the impression that I believe the energetic viewpoint to be completely unfruitful for our discipline, this is not my view. It is entirely proper at some time to take into account the physical and chemical balance sheets of technical and economical developmental processes.... We could benefit from his discussions as well, and certainly his general comment that it is necessary to take into account all of the statements that result from the application of the laws of energy to social phenomenon, deserves our unreserved agreement" [4].

Here Weber acknowledged that the contribution of physical sciences was needed to understand social phenomena. Moreover, for Weber the expansion of capitalism is not conceivable without taking into consideration the availability of energy for its purposes, in the form of potential work, being it living bodies or dead machines:

"For when asceticism was carried out of monastic cells into everyday life, and began to dominate worldly morality, it did its part in building the tremendous cosmos of the modern economic order. This order is now bound to the technical and economic conditions of machine production which today determine the lives of all the individuals who are born into this mechanism, not only those directly concerned with economic acquisition, with irresistible force. Perhaps it will so determine them until the last ton of fossilized coal is burnt" [5].

Émile Durkheim sculpted sociology where the

Corresponding author: dario.padovan@ unito.it 
constraint that social facts exercised upon individuals seemed analogous to natural facts shaping societies. He was also aware, like all his contemporary sociologists, that physical conditions shape societal evolution, however, he claimed a very clear distinction between these two types of coercion, coming from the "physical" or the "social":

"There is a world of difference separating a physical from a moral environment. The pressure exerted by one or several bodies on other bodies or even on other wills should not be confused with that which the group consciousness exercises on the consciousness of its members. What is exclusively peculiar to social constraint is that it stems not from the unyieldingness of certain patterns of molecules, but from the prestige with which certain representations are endowed" [6].

Consequently, he could claim that "even every individual drinks, sleeps, eats, or employs his reason, and society has every interest in seeing that these functions are regularly exercised, these are not social facts. If therefore these facts were social ones, sociology would possess no subject matter peculiarly its own, and its domain would be confused with that of biology and psychology". According to Durkheim, in every society there is a clearly determined group of phenomena separable, because of their distinct characteristics, from those that form the subject matter of other sciences of nature. Here he described a stable separation between natural and social phenomena. Nearly all prominent social theories endorsed this ontology.

In recent decades, the situation has been inverted. Many scholars are calling for the reinsertion of the material in social sciences. As argued by Dave ElderVass [7] "Social entities are often composed of both human agents and non-human material objects, and that both may make essential contributions to their causal influence. In such cases the causal influence of social structures should be attributed to the emergent causal powers of what I call socio-technical entities". I agree that the social is not reducible to some kind of hybridity.

The social order and its causal dynamics stem from a dialectic between the material and the immaterial, the natural and the social, the concrete and the abstract. Human history is always also natural history, because human beings can never completely dissociate themselves from the natural world; nature is inextricably entwined with human history. This "inextricability" takes the form of an "asymmetric dialectic" between ontologies: the "natural" can survive without the "social" and relations with it, but this latter cannot survive without the "nature", it needs always a material basis on which it develops its material living. There is not reciprocity from the side of the "natural" because it expects nothing to return from the "social" in response to its input. This relationship can be defined as "something for nothing". The social, however, expects something from the natural, it expects what it needs to survive. Micheael Carolan theorises the ontological asymmetry that exists between the two realms-namely, that although the biophysical can exist without the social, the converse is categorically impossible. If we conceptualise the two realms as being mutually constitutive of each other, however, then how is this asymmetrical relationship explained? [8].

\section{Energy, material fertility, and capitalism}

Our "living together" is profoundly rooted in and organised around large concentrations of energy and raw materials that support and absorb growing volumes of activities. The civilisations, or cultures of humankind, also, may be regarded as a form or organisation of energy [9]. This observation, that societies or the "forms of human existence" and their differences and powers "are" organisations or forms of energy, might seem trivial, however, it has radical consequences for social theory and for a new reading of the ongoing dynamics of global capitalism.

The global economy depends on energy for the purposes of value creation, profit maximisation and capital accumulation, however, this material and energy regime seems to be completely unsustainable, and increasingly untenable. The horizon that emerges due to the ecological crisis caused mainly by fossil energy use - climate change, nitrogen cycle alteration, biodiversity reduction, peak of fossil energy, peak of raw materials - has crucial and problematic elements for either earth system dynamics or world-ecology reproduction, and global capitalist accumulation. The most important one is the decreasing "natural fertility of capital", in other words the availability of cheap fossil energy and raw materials needed to capture living labour. This dynamic shapes the ratio between dead labour and living labour, between carriers of value and valorising labour, or, in other words, the organic composition of capital. As Marx wrote:

"There is just one thing to be noted here: the natural wealth in iron, coal, wood, etc., which are the principal elements used in the construction and operation of machinery, presents itself here as a natural fertility of capital and is a factor determining the rate of profit irrespective of the high or low level of wages" [10].

Marx sensed that the material basis of the capital accumulation process could shape its magnitude and speed of reproduction. The "natural wealth" here evoked by Marx includes energy carriers such as coal, gas, and wood; raw materials that directly enter the process of production such as cotton, wool, linen, iron; and finally the raw materials used to build machinery, such as iron, wood, leather. Fluctuations in the price of such materials affects the rate of profit, falling and rising inversely to the price of the raw material. This shows, among other things, the importance of the low price of raw materials for global industry.

The most critical aspect of such dynamics is the availability of the fossil energy and raw materials needed to absorb work, support value and keep alive the machine of capital accumulation. A second critical aspect is the inevitability of giving up fossil fuels, 
because of global warming. An energetic reconsideration of the dynamics of capitalism highlights how the relationship between capitalism and energy has gradually become more complex and interdependent. The availability of diversified and intensive fossil energy sources lies at the base of the world's capital expansion and the particularly energetic society that it has been able to generate. Capitalism has transformed the generic external and environmental conditions of its own birth in an internal condition of its own reproducibility and expansion. Fossil energy irreversibly became an internal condition of capitalist accumulation [11, 12], and in doing so also the foundational condition of human reproduction. As acknowledged by Lotka, the economy system is the complex outcome of the combination of endosomatic and exosomatic energy, or, in other words, of the combination of the work of humans, machines, and nature.

\section{Between materiality and immateriality}

Social scientists are often reluctant to reflect upon energy, perhaps because they do not find the object of this reflection very clear. Similar to other notions, such as strength, will, work, and money, energy appears to be both something immaterial, incorporeal, abstract, spiritual, and something material, concrete and physical. This ambivalence is likely the reason that sociologists do not engage in studying energy, or perhaps it is its material side that put sociologists at discomfort.

Energy is evident only in its effects. Energy is not in itself stuff; it is something that all stuff has. In itself, energy remains unknown, a universal abstraction, an elusive subject, a restless activity. As such, in its essence, energy is something inaccessible and prematerial [13]. As claimed by the physicist Frederick Soddy:

"Energy, someone may say, is a mere abstraction, a mere term, not a real thing. As you will. In this, as in many another respects, it is like an abstraction no one would deny reality to, and that abstraction is wealth. Wealth is the power of purchasing, as energy is the power of working. I cannot show you energy, only its effects ... Abstraction or not, energy is as real as wealth - I am not sure that they are not two aspects of the same thing" [14].

The physicist Richard Feynman [15] stressed that we "have no knowledge of what energy is... It is an abstract thing in that it does not tell us the mechanisms or the reasons for the various formula". As noted by Richard Adams, energy forms, equilibrium, structures, and stability describe states or conditions, but they have little meaning, apart from the dynamics through which they are manifest. It is in the quality of inherent dynamics that the concept of the "energy form" becomes useful [16].

Consequently, access to an understanding of energy is possible only through materially experiencing its natural or artificial forms, and the work that it puts in motion. In short, energy cannot be traced back to its pre-materiality, that is, to its abstract existence: it can be known when, after it is captured and transformed by matter or living beings, it becomes work that makes events.

Given the dilemmas it embodies, energy deserves to be approached and carefully scrutinised in a dynamic way, paying particular attention to its transformational and concrete processes. Even though its effects are self-evident, energy remains an abstraction, in two ways: first because of its intrinsic transformational power, and secondly because it represents the intrinsic value of commodities in the form of human energy expenditure. Understanding energy ontology is possible by studying the materiality of its effects, its transformative capacity, its ability to put work into motion, and its centrality in production, distribution and consumption processes. Energy has one source, the sun (the other is geothermal, coming from the earth) but there are many physical carriers, converters, and forms - muscular, kinetic, thermal, electric, gravitational - that constitute its enormous transformative capacity, hence the difficulty of understanding it immediately, in one cognitive system. Energy has a multiple ontology or an ontology made of multiple realities, so it is interesting to try to determine how it moves and what it does.

The idea that we are now living in an economy that tends to immateriality and that economic growth is now decoupled from energy and raw materials consumption is a myth that is difficult to fight. For example, financial markets, which mobilise enormous amounts of fictitious capital, exert rather strong pressures on the so-called real economy, including imposition of the payment by debtors of debts contracted with financial creditors (banks and funds); payments that are only possible if real growth rates remain high. Financial capital indirectly strengthens economic growth and, consequently, the increased consumption of energy and raw materials, although an increase in efficiency in their use can partially offset this trend.

Recent economic crises and financial instability have not only undermined the least inertial social order typical of capitalist societies, but are also fuelled by growing socio-ecological disorder, where many (socio) local ecosystems, and perhaps even the most complex "Earth System", do not respond adequately to the processes of global capitalist accumulation. Capitalism is a system that mobilises enormous quantities of energy and raw materials for the production, distribution, and consumption of commodities, and this is the reason for its high environmental impact. It is also a system that aims to extract increasing quantities of value from any entity capable of generating it, indifferent to the particular form in which it is presented. The ecological crisis thus entails the definitive abstraction of the work of nature, whereas the dead work of nature (the material wealth deposited after eons of work) is under marketisation and is used to capture living labour. 


\section{Work/energy}

The work that energy puts into motion is a key feature of its ontology. Work becomes the key to reading the social dimension of energy. I hold here that the global economic process aims to transform energy and matter, particularly fossil energy-sources, into labour-energy, thus producing commodities and, ultimately, value. The energy capacity which I consider here is not only "the ability to induce a change in a given state of affairs" [17], or again, as said by Smil, "the ability to transform a system" [18]. Here I try to show that energy in its endosomatic form is potential abstract labour that forms the substance of value, as homogeneous human labour, the expenditure of one uniform labour-power, the "expenditure of human brains, nerves, and muscles", even it is mediated by complex technical and organisational machineries. If we distinguish between the concrete character of each kind of labour and the expenditure of labour power common to all these concrete types of labour, as Marx did, it is also possible to distinguish between the concrete characters of each kind of energy form and its abstract expenditure. For instance, when different conventional units and metrics - Joules, Kcalories, $\mathrm{BTU}, \mathrm{KWh}$ - measure energy it means that it is separated from its material carrier, being subjected to a process of abstraction, becoming a matter of exchange, just as happens for the process of labour abstraction.

The Marx definition of abstract labour is in debt to a specific definition of energy - that delivered by earlier physicists such as von Helmholtz [19]. Marx often stresses that commodities and their value represent or embody the simple expenditure of labourpower:

"Let us now look at the residue of the products of labour. There is nothing left of them in each case but the same phantom-like objectivity; they are merely congealed quantities of homogeneous human labour, i.e. of human labour-power expended without regard to the form of its expenditure. All these things now tell us is that human labour-power has been expended to produce them, human labour is accumulated in them. As crystals of this social substance, which is common to them all, they are values - commodity values (Warenwerte)." [2].

Again, "the labour that forms the substance of value is equal human labour, the expenditure of identical human labour-power. The total labour-power of society, which is manifested in the values of the world of commodities, counts here as one homogeneous mass of human labour-power, although composed of innumerable individual units of labour-power" [2].

Again "If we leave aside the determinate quality of productive activity, and therefore the useful character of the labour, what remains is its quality of being an expenditure of human labour-power. Tailoring and weaving, although they are qualitatively different productive activities, are both a productive expenditure of human brains, muscles, nerves, hands etc., and in this sense both human labour. They are merely two different forms of the expenditure of human labour- power. Of course, human labour-power must itself have attained a certain level of development before it can be expended in this or that form. But the value of a commodity represents human labour pure and simple, the expenditure of human labour in general... It is the expenditure of simple labour-power, i.e. of the labourpower possessed in his bodily organism by every ordinary man, on the average, without being developed in any special way." [2].

From a biophysical perspective, however, labour is not a primary, self-renewing force. While labour does reproduce, labour does not create or recycle its own energy. Instead, the existence and reproduction of labour, and consequently of capital, depends on a continual input of low-entropy energy. This energy is derived from the sun either directly (rays, heat) or indirectly (wind, hydraulics), from solar radiation stored in the bonds of fossil fuels (oil, coal, gas), from geothermal flows, and from chemical bonds stored in bio-mass. Energy cannot be created by labour or physical capital (machines). It must instead be recovered from the environment [20]. The labour-force of humans is thus renewed only by using new energy. The physiological capability of labour to generate value depends on this energy. Just as labour is necessary to produce labour, energy is necessary to extract energy from the environment. And just as in a growth economy, labour can produce more than what is necessary for its own reproduction, so the energy extracted from nature is generally greater than the energy expended for its extraction. The ratio of labour obtained to labour expended is a critical magnitude in economics: it is imperative that it be greater than one. Similarly, the surplus corresponding to the difference between energy obtained and energy invested is net energy [21].

As is well known, a crucial factor supporting rising labour productivity throughout time has been the increasing use of energy [22, 23]. This idea, widely accepted among ecological economists, has never fully taken on board by the economy mainstream. A slightly overstated paraphrase is "The currency of the world is not the dollar, it is the joule" [24]. One can make the connection between rising labour productivity and increasing energy use a bit more precise by comparing the growth rates of average labour and energy productivities and the energy/labour ratio [25].

The relationship of thermodynamics to work is explicit. Capital is concerned with physical work because the labour-process is the transformation of labour-power (energy, inertia) into labour (work). This is the "eternal necessity" of capital, and physics provides models for overcoming "resistances" and measuring rods for levels of crisis [26]. For Caffentzis, the problem is not the lack of energy or the quantity of work per se, but the proportion of work generated by energy (or labourpower), the ratio between the two. Capital is not just a product of work. Capital is the process of workcreation, the condition for transforming energy into work, but energy is the pre-condition of this transformation. Although the eternal cycle of capitalist reality is the transformation of energies into work, its 
problem is that unless certain quantitative levels are reached, the relationship expressed in the work/energy ratio collapses, and entropy increases.

\section{Energy as social relationship}

Beyond the thermodynamic complex that it can represent, the work/energy ratio is a social relationship. It is the matrix in which a variety of human agents and mechanical artefacts are organised in order to perform practices of production to generate value. Production entails a form of nature appropriation, however. It thus becomes the social matrix that generates forms of work to produce commodities and forms of work to appropriate nature at the same time, the way in which nature is organised in order to be appropriated. Here energy becomes the material link between the social nature of human organisation and the social nature of nature organisation, the power that innerves the organisational processes to appropriate nature. Energetic relations become relationships of power in which processes of nature appropriation are deployed. Here energy can be seen as a historical determination that applies to concrete societies and their organisation.

Forms of energy (muscles, wind, water, and fuel powered machines) depend on the prevalent historical social relations between classes and modes of reproduction. Those relationships that select the prevalent energy form, from which depends the time space configurations and the general livelihood of a society or a social system, or a collective mode of existence, are relationships of exchange between society and nature. The use of energy is socially organised and technologically structured. It enables the delivery of natural resources to social groups in forms that can be readily used (as food, goods, and so on). In short, the use of energy allows natural resources to be socially configured and allocated in ways that can both enhance and limit the evolution of human societies [9, $27,28]$. Despite the fact that energy can be defined as "the ability to do work," natural scientists are rarely concerned about the type of work being made possible and how this changes in time and space [29]. Briefly, we can say that energy configurations ultimately aim to allow bundles of social activities, arrays of social practices intended to produce and consume commodities.

The social essence of energy enables us to avoid an "energetic determinism" that is divorced from its true social, political, and economic basis. As noted by Matthew Huber, "while energy matters, it is important to retain a perspective of dialectical complexity that emphasises the mutually constitutive relations between energy and society" [30]. The shift from productive systems based on the application of human and animal muscle power to systems based on "inanimate", or nonliving, power represents a fundamental transformation in the "labour process", or in the socio-natural metabolism [31-33].

Energy appropriation and consumption is always mediated by labour and machinery. Only the simplest forms of energy can be harnessed without infrastructure. Energy resources are always transformed by a combination of technical systems [34, 35 ] and human labour that give them a particular social configuration in order to make human and technical apparatuses work, to sustain the metabolic reproduction of a number of different social subsystems [36-38]. Energy has many material carriers, however - sun, oil, coal, gas, wind, bio-mass - that in capitalist society become commodities essential in the production of all other commodities (including labour power). Energy as labour - is intrinsically ambivalent: it is a use-value freely provided by nature, and vital for all living systems (social and biological), but it is also a commodity that shares rules of production, circulation, and consumption with other commodities. It is at the same time a gift from nature and a commodity that can be controlled through technical processes according to a purely economic logic. It has been considered implicitly neutral, unlimited and inexhaustible, devoid of any particular impact on the future of society, subordinate to this future, adaptable at will [39], but it is now becoming a very sensitive issue due to its effects on climate chaos.

\section{The metabolic cleavage}

The social metabolism or the resource throughput between physical nature and human society is activated and mobilised by labour. As suggested by Swyngedouw [33] the metabolic process is energised through the fusion of the physical properties and creative capacities of humans with those of nonhumans. It is through labour that raw materials are transformed into use values and are given a specific exchange value due to their capacity to be exchanged. As Marx suggested, without the input of concrete labour (or energy to drive machines to replace concrete labour) there would be no metabolism.

Although labour is changed over time, it remains the main action with which to appropriate and transform nature - energy and raw materials - while producing wealth and value. Firstly, labour is an appropriative action implied in the practices of selection, extraction and relocation of an amount of natural elements, putting them at the disposal of other practices [40]. The array of services freely provided by nature and freely appropriable and usable by society (such as bio-mass or nitrogen) can be counted as pure appropriation. These ecosystem services, now becoming a diffuse concept for attracting attention to societal dependence from ecological life support systems [41], are one of the clearest examples of the free metabolic exchange between society and nature. As suggested by Marx: "All those things which labour merely separates from immediate connection with their environment are objects of labour spontaneously provided by nature, such as fish caught and separated from their natural element, namely water, timber felled in virgin forests, and ores extracted from their veins" [2]. 
By contrast, agricultural labour-processes are primarily deployed to sustain or regulate the environmental conditions under which seeds or stock animals grow and develop. There is a transformative moment in these labour processes, but the transformations are brought about by naturally given organic mechanisms, not by the application of human labour [40].

Finally we have a concept of the labour-process where the notion of a raw material undergoing a transformation to yield a use value is central. This transformation is the outcome of human labour, which involves the utilisation of raw materials and instruments of labour to achieve its purpose. The process involves both intentional human activity, and a range of distinct materials, substances and other nonhuman beings and conditions. Benton describes different proportions and activities performed by humans and nature in the process of production to understand how labour mediates and bridges society and nature. In this view, labour is seen as a metahistorical process of human adaptation to environmental conditions of social reproduction.

The labour capacity to adapt humans to nature, before its distortion due to its subsumption and abstraction caused by capitalism, was clearly underlined by Marx: "Labour is, first of all, a process between man and nature, a process by which man, through his own actions, mediates, regulates and controls the metabolism between himself and nature. He confronts the materials of nature as a force of nature. He sets in motion the natural forces, which belong to his own body, his arms, legs, head and hands, in order to appropriate the materials of nature in a form adapted to his own needs. Through this movement he acts upon external nature and changes it, and in this way he simultaneously changes his own nature." [2].

"In the labour process, therefore, man's activity, via the instruments of labour, effects an alteration in the object of labour which was intended from the outset. The process is extinguished in the product. The product of the process is a use-value, a piece of natural material adapted to human needs by means of a change in its form. Labour has become bound up in its object: labour has been objectified, the object has been worked on." [2].

Under capitalist conditions, labour becomes an intentional form of socially organised activity usually involving the use of technical tools, science, and expert knowledge [42], which aims to transform energy, matter and living organisms into objects for social needs, but also able at the same time to generate economic value. While labour is understandable as the transformation taking on the world, the engine of the concrete material colonisation of nature, it is also a dynamic tool for the abstraction of the world. As suggested by Robert Kurz [42], in contrast to premodern societies, the "process of metabolism with nature" is no longer codified by religious traditions and traditional grammars, but is now mediated through the mechanism of the market, which progressively incorporates the entire relationship to nature through the process of abstraction of the commodity form. Capitalism entails the transformation of the material and sensible content of reproduction into "abstract things", whose phenomenal form is money, indifferent to that content. Paradoxically, the process of abstraction of labour renders humans much more dependent on social relations within the "process of metabolism with nature" than they were in pre-modern society, which was characterised in this respect by small autarchic units of production [42].

If metabolism is nothing but the continuous process of assembling and reassembling past and present energy, matter and labour, where labour is energy transferred to a human organism by means of nourishing matter, under capitalist social relations the separation of society from nature is accomplished but only to subsume it under new forms of exploitation. While separation is at work, it allows the forced unity of society/nature complex ascribed by dualistic ways of thinking to each term. Thus, under the term "production of nature" we can see the dialectical movement between separation and unification of society/nature complex [43, 44].

The subsuming process arises, as noted by Kurz, from a blind social machine for the abstract utilisation of labour power, whose tendency consists of absorbing within its vacant movement humans, nature and everything that it touches, directing them and later evacuating them into the other dead form of labour and matter, without adding any other qualitative end. This social machine has to put material quality into motion: raw materials, natural forces and living human labour; such qualities, however, do not constitute a goal nor do they produce any end by themselves, they are only the means in the tautological and self-referential process of abstract labour. There is, therefore, a reversal of means and ends: labour is no longer a means towards the qualitative end of the appropriation of nature, but, conversely, the qualitative and material appropriation of nature is only an indifferent means for the process of the change of form of abstract labour as an end-in-itself [45].

\section{Conclusions}

In this paper, I have tried to show how that social sciences can help to understand the variation of physical world, from climate change to shortage of energy and raw materials. The job of social scientists can suggest that the so-called ecology world crisis interacts with the capitalist crisis. The changing conditions of energy and raw materials availability shape the global process of capital accumulation and the way in which capital recruits living labour to maintain the conditions of accumulation. The social dynamics of the carriers of value, of the material absorbers, capturers, engagers, attractors of living abstract labour are also changing, and this requires deep investigation. The dynamics of dead labour as raw materials, energy, and means of production that are 
become commodities entering the process of production, deserve more attention because they are crucial for the process of valorisation: without coal, oil, iron, cotton, and cereals, the accumulation process ends. Consequently, variations in terms of the natural fertility of capital profoundly shape its health and wealth. Without biomass, raw materials, and energy withdrawn from earth, the capital reproduction would not exist. The crisis on the horizon is a crisis not only of the productivity of the labour recruited by capital, but also a crisis of natural fertility, which means increasing labour and energy to recruit nature into the process. Workers and nature are therefore allies here, even against their wills.

Energy and raw materials are the battleground on which the survival of global capital will depend, and they are at the same time the battleground among competing capitals - national and sectorial capitals - to gain access or to conserve resources. As Gedicks [46] argued, Marx not only recognised the importance of low-cost resources for capital accumulation, but felt that the scarcity of these resources at a low price could threaten advanced capitalist countries, particularly if technological advances could not keep pace with a declining resource base. This means that the horizon upon which the globalised capital is moving is still that of crisis, but also means that these socio-material fields - such as energy and raw materials availability - are becoming more crucial than others for a transitional politics beyond capitalism. Many of the strategies emerging to accomplish this transition are not effective. Only a few - at least until now - aim to go beyond the present system, replacing forms of alienated and abstract work and nature with fewer work- and energy-based reproducing processes.

\section{References}

1. R. Murphy, Sociology as If Nature Did Not Matter: An Ecological Critique, Br. J. Soc., 46, 4 (1995).

2. K. Marx, Capital Vol I, Penguin Books Ltd, Harmondsworth (1976).

3. W. Ostwald, Energetische Grundlagen der Kulturwissenschaft [Energetic Foundations of a Science of Culture], Philosophical-Sociological Library, ed. by Rud. Ersler, Vienna, Vol. XVI W. Klinkhardt, Leipzig (1909).

4. M. Weber, "Energetic" Theories of Culture (1909), Mid-American Review of Sociology, 9, 2 (1984).

5. M. Weber, The Protestant Ethic and the Spirit of Capitalism, Routledge, London-New York (2001) (orig. ed 1905/20).

6. É. Durkheim, The Rules of Sociological Method, Free Press, New York (1982) (orig. ed 1893).

7. D. Elder-Vass, Material Parts in Social Structures, Journal of social ontology, 3, 1, 89-105 (2017).

8. M. S. Carolan, Society, Biology, and Ecology: Bringing Nature Back Into Sociology's Disciplinary Narrative Through Critical Realism,
Organization \& Environment, 18, 4, 393-421 (2005).

9. L. A. White, Energy and the Evolution of Culture, American Anthropologist, 45, 335-356 (1943).

10. K. Marx, Capital Vol. III, Lawrence \& Wishart, London (2010).

11. E. Altvater, The social formation of capitalism, fossil energy, and oil-imperialism, Centre for Civil Society Colloquium on the Economy, Society and Nature, University of KwaZulu Natal (2006).

12. A. Malm, Fossil Capital. The Rise of Steam Power and the Roots of Global Warming, Verso, London (2016).

A. S. T. Vadén, Energy and Experience: An Essay in Nafthology, MCM' Publishing, Chicago, Alberta (2015).

13. F. Soddy, Science and Life, Dutton, New York (1920).

14. R. P. Feynman, The Feynman Lectures on Physics, Vol. 1, Addison-Wesley, Pearson, Boston (1963).

15. R. N. Adams, The Eighth Day. Social Evolution as the Self-Organization of Energy, University of Texas Press, Austin (1988).

16. M. Giampietro, K. Mayumi, Complex Systems Thinking and Renewable Energy Systems, in David Pimentel. (ed.), Biofuels, Solar and Wind as Renewable Energy Systems Benefits and Risks, Springer, Berlin (2008).

17. V. Smil, Energy in Nature and Society: General Energetics of Complex Systems, MIT Press, Cambridge, MA (2008).

18. A. Rabinbach, The Human Motor: Energy, Fatigue, and the Rise of Modernity, Basic Books, New York (1990).

19. R. Kaufmann, Biophysical and Marxist economics: learning from each other, Ecological Modelling, 38, 91-105 (1987).

20. M. O'Connor (Ed), Is capitalism sustainable?, The Guilford Press, New York (1994).

21. J. Martínez-Alier, K. Schlüpmann, Ecological Economics: Energy, Environment, and Society, Basil Blackwell, Oxford, New York (1987).

22. P. Mirowski, More Heat than Light, Cambridge University Press, Cambridge (1989).

23. N. S. Lewis, Powering the Planet, MRS Bulletin, 32, 808-820 (2007).

24. L. Taylor, Energy Productivity, Labor Productivity, and Global Warming in J. M. Harris, N. R. Goodwin (eds.) Twenty-First Century Macroeconomics: Responding to the Climate Challenge, Edward Elgar, Northhampton MA (2008).

25. G. Caffentzis, In Letters of Blood and Fire: Work, Machines, and the Crisis of Capitalism, PM Press, Oakland (2013).

26. R. N. Adams, Energy and Structure: A Theory of Social Power, University of Texas Press, Austin (1975).

27. L. Lutzenhiser, Sociology, Energy and Interdisciplinary Environmental Science, The American Sociologist, 25, 58-79 (1994).

28. E. Shove, G. Walker, What Is Energy For? Social 
Practice and Energy Demand, Theory, Culture and Society, 31, 5, 41-58 (2014).

29. M. T. Huber, Energizing historical materialism: Fossil fuels, space and the capitalist mode of production, Geoforum, 40, 105-115 (2008).

30. J. B. Foster, Marx's Ecology, Monthly Review Press, New York (2000).

31. N. C. Heynen, M. Kaika, E. Swyngedouw (eds), In the Nature of Cities: Urban Political Ecology and the Politics of Urban Metabolism, Routledge, Abingdon (2006).

32. E. Swyngedouw, Circulations and metabolisms: (Hybrid) natures and (Cyborg) cities. Science as Culture 15, 2, 105-121 (2006).

33. V. Smil, Energy Transitions, Praeger, Santa Barbara, CA (2010).

34. D. Tyfield, King Coal is Dead! Long Live the King!. The Paradoxes of Coal's Resurgence in the Emergence of Global Low-Carbon Societies, Theory, Culture \& Society, 31, 5, 59-81 (2014).

35. D. Padovan, Assembling societal metabolism and social practices: the dynamics of sustainable and unsustainable reproduction, in P. Strandbakken and J. Gronow (Eds), The Consumer in Society. A tribute to Eivind Sto, Abstrakt Forlag AS, Oslo, (2015).

36. D. Padovan, Metabolic exchanges and practices of regulation. The assemblage of environment and society in early social sciences", Ecol. Inf., 6-17 (2015).

37. D. Padovan, F. Martini, A. K. Cerutti, Social Practices of Ordinary Consumption: An Introduction to Household Metabolism. Journal of Socialomics, 4, 2, 1-11 (2015).

38. J.-C. Debeir, J.-P. Deleage, D. Hemery, In the Servitude of Power Energy and Civilization Through the Ages, The University of Chicago Press, Chicago (1991).

39. T. Benton, Marxism and natural limits, New Left Review, 178, 51-86 (1989).

40. E. Gómez-Baggethun, R. de Groot, P. L. Lomas, C. Montes, The history of ecosystem services in economic theory and practice: From early notions to markets and payment schemes, Ecol. Econ. 69, 1209-1218 (2010).

41. S. Sayers, The concept of labor: Marx and his critics. Science \& Society, 71, 4, 431-454 (2007).

42. R. Kurz, The end of politics: theses on the crisis of the regulatory system of the commodity form. Originally published in German as "Der Ende der Politik" in Krisis No. 14, Horlemann Verlag, Bad Honnef (1994).

43. J. W. Moore, Ecology and the accumulation of capital. Paper Presented at Workshop, Food, Energy, Environment: Crisis of the Modern WorldSystem, Fernand Braudel Center, Binghamton University (2009).

44. N. Castree, Marxism, capitalism, and the production of nature, in N. Castree, B. Braun (Eds.), Social Nature: Theory, Practice and Politics, Wiley-Blackwell, Oxford, 189-207 (2001).
45. R. Kurz, The lost honour of labour. Original German text: "Die verlorene Ehre der Arbeit", in Krisis, 10, Erlangen (1991).

46. A. Gedicks, Raw materials: the Achilles heel of American imperialism?, Insurgent Sociology, 7, 313 (1977). 